\title{
Actionable Assessment of Iron Stores in Blood Donors
}

\begin{abstract}
Before blood donation, blood banks screen potential donors for low hemoglobin or hematocrit, usually in blood drops obtained through finger prick. Although different technologies exist for this, including a couple of non-invasive systems, all detect anemia and prevent that anemic people give blood. However, a reasonable number of people bear sideropenia without anemia, and should not donate blood either. Nowadays, they do. To understand this issue better, to identify these invisible unfit blood donors, and to design costeffective ways to detect and protect them, we evaluated erythrocyte zinc protoporphyrin and serum ferritin in a cohort of 315 blood donors. In addition, we evaluated the number of blood donors bearing iron overload, invisible as well among donors, and discuss the importance of the extension of blood banks as epidemiological surveillance centers for iron metabolism disorders.
\end{abstract}

Keywords: iron deficiency, iron overload, blood donors, zinc protoporphyrin, ferritin
Volume 9 Issue 2 - 202 I

Estácio Ferreira Ramos MD

Department of Hematology, Blood Banking, Brazil

Correspondence: Estácio Ferreira Ramos, M.D., CYTOMICA, Inc, Rua Bela Vista do Cabral 62/0I, Nazaré, Salvador, CEP 40055-000, Brazil, Email ceo@cytomica.com

Received: January 21, 2021 | Published: April 30, 2021

\section{Introduction}

In the final steps of heme synthesis, ferrochelatase inserts iron atoms into protoporphyrin IX driving to the assembly of tetrameric hemoglobin molecules. In iron deficiency, or if the enzyme is impaired as in lead poisoning, some zinc enters protoporphyrin molecules, generating a minimal amount of zinc protoporphyrin $(\mathrm{ZnPP})$ in red cell cytosol, a non-functional metalloporphyrin. The ratio $\mu$ moles of $\mathrm{ZnPP} / \mathrm{moles}$ of heme increase in sideropenia and/or saturnism. The test is quantitative, especially sensitive and very specific for both conditions; one blood drop is enough for the test, performed in seconds. Ferritin is a large protein made of 24 monomers of apoferritin that shape a hollow sphere. It exists in almost every cell as the main protein of iron metabolism, especially concentrated in bone marrow, liver and spleen. Ferritin participates in iron uptake, storage, protection against oxidation and delivery of iron to cell economy. Each molecule can carry 4.000 atoms of $\mathrm{Fe} 3+$ and its concentration in plasma reflects iron stores.

In this study, we used zinc protoporphyrin in 315 blood donors to unveil iron deficiency and eventual lead poisoning. In addition, we used ferritin to confirm and measure iron deficiency and to unveil iron overload states in blood donors.

\section{Material and methods}

We obtained and tested EDTA whole blood and serum samples from random blood donors, post donation $(n=315 \mid$ males $=245 \mid$ females

Table I ZnPP and ferritin in blood donors
$=70$ ). All passed the hemoglobin screening; the cut-off for anemia in women was $11.8 \mathrm{~g} / \mathrm{dL}$, and for men $13.8 \mathrm{~g} / \mathrm{dL}$. Ages varied from 18 to 57 years old. All samples were refrigerated, $48 \mathrm{~h}$ old, seronegative for transmissible diseases, and for HBV, HCV and HIV by nucleic acid testing. All samples were pre-warmed to $37^{\circ} \mathrm{C}$ under slight agitation, before tests. ZnPP measured in EDTA whole blood using a Hematofluorometer (Protofluor Z, Helena Laboratories ${ }^{\circledR}$ ) and the cutoff ratio used for iron deficiency and/or saturnism was $64 \mu \mathrm{mol} / \mathrm{mol}$ of heme for both genders. Ferritin determinations performed through ADVIA Centaur ${ }^{\circledR}$ chemiluminometric immunoassay, the adopted cut-offs for iron deficiency were $30 \mathrm{ng} / \mathrm{mL}$ for males and $20 \mathrm{ng} / \mathrm{mL}$ for females. Cut-offs for iron overloads were $400 \mathrm{ng} / \mathrm{mL}$ for males, and $150 \mathrm{ng} / \mathrm{mL}$ for females.

\section{Results}

Results are straightforward, summarized in the Table 1 and discussed ahead. In males, mean ferritin was $121 \mathrm{ng} / \mathrm{mL}$ and mean ZnPP was $26.9 \mu \mathrm{mol} / \mathrm{mol}$ of heme; $2.04 \%$ of males had low ferritin, and $1.22 \%$ had elevated $\mathrm{ZnPP} / \mathrm{heme}$ ratio, mean $128.1 \mu \mathrm{mol} / \mathrm{mol}$ of heme. Regarding iron overload, $5.71 \%$ of males had ferritin above $400 \mathrm{ng} / \mathrm{mL}$. Two out of the 16 donors with iron overload had ferritin above $1.400 \mathrm{ng} / \mathrm{mL}$. In females, mean ferritin was $67.1 \mathrm{ng} / \mathrm{mL}$ and mean $\mathrm{ZnPP}$ ratio was $43 \mu \mathrm{mol} / \mathrm{mol}$ of heme. Ten percent had low ferritin and $8.62 \%$ had elevated $\mathrm{ZnPP} /$ heme ratio (mean $171 \mu \mathrm{mol} /$ mol of heme). Only $2 \%$ of women had ferritin levels above $200 \mathrm{ng} /$ $\mathrm{mL}$. Overall, mean ferritin in blood donors was $94.2 \mathrm{ng} / \mathrm{mL}$ and around $4 \%$ of them have sideropenia and $5 \%$ bear iron overload.

\begin{tabular}{|c|c|c|c|c|c|c|c|}
\hline \multicolumn{2}{|c|}{ Blood donors } & \multirow{2}{*}{$\begin{array}{l}\text { All } \\
315\end{array}$} & \multirow{2}{*}{$\begin{array}{l}\% \\
100.00\end{array}$} & \multirow{2}{*}{$\begin{array}{l}\text { Males } \\
245\end{array}$} & \multirow{2}{*}{$\begin{array}{l}\% \\
77.77\end{array}$} & \multirow{2}{*}{$\begin{array}{l}\text { Females } \\
70\end{array}$} & \multirow{2}{*}{$\begin{array}{l}\% \\
22.33\end{array}$} \\
\hline & & & & & & & \\
\hline \multirow[t]{2}{*}{ ZnPP } & NORMAL & 299 & 94.92 & 238 & 97.56 & 61 & 91.28 \\
\hline & $\mathrm{HIGH}$ & 11 & 3.49 & 3 & 1.22 & 8 & 8.62 \\
\hline \multicolumn{2}{|c|}{ FERRITIN NORMAL } & 300 & 95.23 & 239 & 97.56 & 61 & 87.14 \\
\hline & LOW & 12 & 3.80 & 5 & 2.04 & 7 & 10 \\
\hline & $\mathrm{HIGH}$ & 16 & 5.07 & 14 & 5.71 & 2 & 2.85 \\
\hline
\end{tabular}




\section{Discussion}

We verify that the use of $\mathrm{ZnPP}$ and ferritin to assess iron metabolism is enough to properly detect iron deficiency and iron overload in blood donors. The use of both tests in this cohort confirms that the anemia screenings in blood banks nowadays fail to detect donors with early or borderline iron deficiency, as pointed out by others. ${ }^{1-4} \mathrm{ZnPP}$ precisely diagnosis iron deficiency, and ferritin informs on its intensity. Some researchers argue that ferritin alone is not adequate for iron deficiency assessment in blood donors.

In men, iron deficiency in the apparently healthy donor may be a signal of excessive blood donations, poor iron intake, use of aspirin or early disease, being hardly acceptable to draw their blood, use it to improve or save other people's lives, leaving them with anemia and undiagnosed. In women, sideropenia relates to young age, diet, vegetarianism, IUD, tubal ligation and other gynecological issues.

Eventually, finding donors with normal ferritin and high ZnPP can lead to the diagnosis of lead poisoning, a serious condition that demands medical care. In theory, it is unacceptable to transfuse their blood, but they are still invisible at blood centers. No lead poisoning was detected in this cohort. Ferritin allows the recognition of iron overload as well, and these donors could benefit from the diagnosis, and eventually, from more blood donations. In this cohort, two male donors got hemochromatosis and probably do not know about it. Besides, above $5 \%$ of donors have higher ferritin without disease, and should be encouraged to make more donations to prevent oxidative stress and future diseases. In other words, blood banks can benefit these donors and benefit from their regular donations.

Actually, through a cornucopia of laboratory tests, algorithms, compatibility and identification systems and technologies, blood banks efficiently protect the recipients of blood components transfusions. However, unfit blood donors with low iron stores are not recognized. Although they look healthy before donation, they instantly become anemic and iron deficient after bleeding, unable to rebuild their hemoglobin. Some may bear early severe diseases. Zinc protoporphyrin is a rather neglected, cost-effective and excellent marker of iron deficiency, ${ }^{5}$ never used in blood banks in Brazil. Someday, it will be part of the pre-donation screening of blood donors everywhere, in a future where all sideropenia will prevent donation. In this future, we expect, non-invasive or automated technologies will make ZnPP measurements even simpler.

\section{Conclusion}

Although iron stores are rather variable in different populations, this study it confirms the existence of sideropenia in approximately $3.8 \%$ of blood donors in a private blood center. Byproducts of this evaluation for iron deficiency, ZnPP uncovers lead poisoning, and ferritin unveiled iron overloads in approximately $5.5 \%$ of our donors.
We understand blood banks should monitor iron stores of blood donors. This test combination is excellent and practical - it is our suggestion, blood centers must adopt it. ZnPP is not labor intensive and can be use in the pre-donation phase to prevent donation. The equipment is portable. Ferritin must be included in the serological routine. Unquestionably cost-effective, these tests can benefit around $15 \%$ of all blood donors with actionable information. Sideropenia detected, donors shall know about its significance, refrain from donations for some time, while medicated and recovering. Men with unexpected sideropenia require medical attention. Those with intermediate high ferritin must be encouraged to frequent donations, and donors with very high ferritin or with suspected lead poisoning must receive medical care.

Although we do recognize we fail to provide desirable information on blood donors, such as donation frequency, the blood donors in this system are not frequent donors, they are replacing donors; and actually, this is irrelevant for the conclusions achieved. Blood banks need to evolve and develop ways to protect better one of the most important assets of human societies - its blood donors.

\section{Acknowledgments}

None.

\section{Conflicts of interest}

The author declares no conflicts of interest.

\section{Funding}

This work did not receive any specific grant from funding agencies in the public, commercial, or not-for-profit sectors.

\section{References}

1. Ron B Schifman, Shirley L Rivers, Paul R Finley, et al. RBC Zinc Protoporphyrin to Screen Blood Donors for Iron Deficiency Anemia. JAMA. 1982;248(16):2012-2015.

2. Romero MS, Puente F, Abós Guitiérez M. Incidence of iron deficiency in a group of 922 altruistic blood donor candidates. Sangre. 1989;34(2):126129.

3. Cançado RD, Chiattone CS, Alonso FA, et al. Iron deficiency in blood donors. São Paulo Med J. 2001;119(4):132-134.

4. Baart AM, van Noord PA, Vergouwe Y, et al. High prevalence of subclinical iron deficiency in whole blood donors not deferred for low hemoglobin. Transfusion. 2013;53(8):1670-1677.

5. Richard R Gammon, Tania Kozel Patrick Morel, et al. Laboratory Evaluation of Iron Stores by Zinc Protoporphyrin Analysis in Blood Donors. Medicine. 2018;49(4):311-315. 